SUBJECT AREAS:

PHOTOCATALYSIS

METAL COMPLEXES

Received

25 October 2013

Accepted

23 January 2014

Published

10 February 2014

Correspondence and requests for materials should be addressed to Z.-T.Y. (yuzt@nju.edu. cn) or Z.-G.Z. (zgzou@ nju.edu.cn)

\section{Hydrogen Photogeneration Promoted by Efficient Electron Transfer from Iridium Sensitizers to Colloidal $\mathrm{MoS}_{2}$ Catalysts}

\author{
Yong-Jun Yuan, Zhen-Tao Yu, Xiao-Jie Liu, Jian-Guang Cai, Zhong-Jie Guan \& Zhi-Gang Zou
}

National Laboratory of Solid State Microstructures and Eco-Materials and Renewable Energy Research Center, Department of Materials Science and Engineering, College of Engineering and Applied Sciences, Nanjing University, Nanjing 210093, P.R. China.

We report the utilization of colloidal $\mathrm{MoS}_{2}$ nanoparticles (NPs) for multicomponent photocatalytic water reduction systems in cooperation with a series of cyclometalated Ir(III) sensitizers. The effects of the particle size and particle dispersion of $\mathrm{MoS}_{2} \mathrm{NPs}$ catalyst, reaction solvent and the concentration of the components on hydrogen evolution efficiency were investigated. The $\mathrm{MoS}_{2} \mathrm{NPs}$ exhibited higher catalytic performance than did other commonly used water reduction catalysts under identical experiment conditions. The introduction of the carboxylate anchoring groups in the iridium complexes allows the species to be favorably chem-adsorbed onto the $\mathrm{MoS}_{2}$ NPs surface to increase the electron transfer, resulting in enhancement of hydrogen evolution relative to the non-attached systems. The highest apparent quantum yield, which was as high as $12.4 \%$, for hydrogen evolution, was obtained $(\lambda=400 \mathrm{~nm})$.

nspired by the natural process of photosynthesis, the hydrogen produced by an artificial system using energy from the sun is emerging as one of the most fascinating approaches suitable for the conversion and storage of solar energy ${ }^{1-3}$. This scheme requires the use of sensitizers in a multicomponent solution that are essential for capturing, delivering and converting solar energy and later storing it in the form of chemical bonds in a highenergy density fuel, such as hydrogen, with the aid of catalytically active sites ${ }^{4-11}$. The development of such an artificially intermolecular system requires a fundamental understanding of electron-transfer reactions between the individually constructed components for interesting catalytic reactions. In recent years, considerable progress has been achieved in developing highly absorbing photosensitizers (PSs) and noble-metal-free water reduction catalysts (WRCs $)^{12-17}$. The use of iridium PSs with transition metal-based WRCs, such as cobalt or iron complexes, has been shown to be preferable because such systems typically possess remarkable activity with a limited operational lifetime for the formation of hydrogen from water ${ }^{18-21}$. The existence of metal-carbon sigma bonds in cyclometalated $\operatorname{Ir}(\mathrm{III})$ emissive species improves their photostability compared to $\mathrm{Ru}(\mathrm{II})$ diimines under illumination $^{22}$. However, for these artificial systems, the photodecomposition of both the sensitizer and catalyst remains a problem that terminates the practical water-splitting reaction in the production of clean fuel ${ }^{23}$. For solar fuel conversion, the stability under catalytic functional conditions is a critical issue that has led to the search for long-term sustainable artificial systems in which PSs and WRCs are capable of withstanding degradation, which continues to be a central challenge in the development of solar fuels.

To address this issue, many approaches have been employed to improve the durability of iridium PSs, such as placing bulky pendant groups on the backbone of the cationic iridium complexes due to their steric protection ${ }^{24}$ or using neutral tris-cyclometalated iridium complexes due to their intrinsic high stability to photolysis ${ }^{25-27}$. In addition to the rhodium, palladium or platinum WRCs, molecular catalysts based on cobalt ${ }^{18,19}$, iron ${ }^{20,21}$ and nicke $^{28}$ have been suggested as cheaper alternatives, but there is still abundant room for improvement of the catalysts' stability. In the search for stable photocatalytic systems, we are interested in highly dispersed inorganic nanoparticles (NPs) as working catalysts that can reduce water to hydrogen in the solution phase. Such nanomaterials with superior photostability are particularly attractive for performing this reaction because redox catalysis can be independently optimized by varying the size, shape or surface ligands of the NPs. Molybdenum disulfide appeared to be a promising candidate because it is active for the evolution of $\mathrm{H}_{2}$ at low electrochemical overpotentials for water reduction, which has been identified as an electrocatalyst and a semiconducting photocatalyst for the heterogeneous hydrogen evolution reactions ${ }^{29-34}$. Few investigations have investigated the reduction of water in multicomponent photochemical molecular systems involving the 
utilization of inorganic catalysts composed of earth-abundant elements because NPs in a stable colloidal form are needed for such applications in aqueous media. Early studies have shown that colloidal $\mathrm{MoS}_{2}$ is active as a WRC replacement for traditional Pt group metal catalysts for hydrogen photoproduction. However, colloidal $\mathrm{MoS}_{2}$ exhibited rather undesirable photocatalytic lifetimes and approached a turnover number (TON) of only 75 with cationic $\left[\mathrm{Ru}(\text { bpy })_{3}\right]^{2+}$ (bpy $=2,2^{\prime}$-bipyridine) chromophores ${ }^{35}$. For further progress with this interesting catalyst, higher conversion efficiencies are required for solar fuel conversion. In addition, a better understanding of the interaction between the new sensitizers and the dispersed $\mathrm{MoS}_{2}$ NPs in the photocatalytic fuel-forming reaction is essential.

To this end, we developed multicomponent hydrogen production systems based on a series of Ir(III) PSs (as shown in Fig. 1) in combination with the colloidal $\mathrm{MoS}_{2}$ WRC. This series allows for the evaluation of the photohydrogen-evolution activity as a function of structure. Due to the functional groups on the PSs, different potential interactions may exist between the PSs and the $\mathrm{MoS}_{2}$ NPs, which may directly interfere with the overall efficiency of the solar energy conversion. In particular, iridium PSs that were functionalized with pendant carboxylic acids as anchoring groups might allow for binding of the molecule chemisorbed onto the surface of the colloidal catalyst to promote electron transfer, which appears to be important for catalytic activity. By controlling the size of the colloidal $\mathrm{MoS}_{2}$ NPs, the selected systems have the ability to produce remarkably high amounts of $\mathrm{H}_{2}$ with an apparent quantum yield (AQY) of up to $12.4 \%$. Further investigation reveals that colloidal $\mathrm{MoS}_{2}$ exhibits desirable activity and long-term stability, which holds great promise<smiles></smiles><smiles></smiles>

3-5 for continuing progress in the clean and sustainable production of hydrogen with novel photocatalytically active materials.

\section{Results}

Characterization of colloidal $\mathrm{MoS}_{2}$ nanoparticles and $\operatorname{Ir}(\mathrm{III})$ complexes. The transparent colloidal $\mathrm{MoS}_{2}$ suspensions were obtained according to a previously published protocol ${ }^{35}$. The poly(vinylpyrrolidone) (PVP) was used as a surface ligand to stabilize the NPs in a fine colloidal state in the aqueous solution. The colloidal suspension of $\mathrm{MoS}_{2}$ clearly displayed a typical Tyndall effect, suggesting the formation of stable $\mathrm{MoS}_{2}$ NPs (Supplementary Fig. S1), and the colloidal suspension was notably stable (no deposition) for several weeks under an air atmosphere. Xray photoelectron spectroscopy (XPS) was utilized to characterize the chemical states of Mo and S in the colloidal NPs. The binding energies of Mo $3 \mathrm{~d}_{3 / 2}$, Mo $3 \mathrm{~d}_{5 / 2}$, $\mathrm{S} 2 \mathrm{p}_{1 / 2}$ and $\mathrm{S} 2 \mathrm{p}_{3 / 2}$ were determined to be 232.1, 228.8, 162.8 and $161.7 \mathrm{eV}$, respectively, indicating the presence of a tetravalent molybdenum ion $\left(\mathrm{Mo}^{4+}\right)$ and a divalent sulfur ion $\left(\mathrm{S}^{2-}\right)$ in the resulting colloidal solution. Quantification by XPS indicated a Mo to $S$ ratio of approximately $1: 2$, which showed that the NPs were present in the form of $\mathrm{MoS}_{2}$. Transmission electron microscopy (TEM) images showed that $\mathrm{MoS}_{2}$ NPs were well-dispersed and appeared to be spherical (Fig. 2a-e). As revealed by the TEM, the dispersion and size distribution of the colloidal $\mathrm{MoS}_{2}$ NPs was controlled by adjusting the ratio of the stabilizer of PVP to $\mathrm{MoS}_{2}$. When a ratio of 40 or 80 was used, the majority of the colloids were less than $10 \mathrm{~nm}$ in diameter with better dispersion. When less PVP was added, a small fraction of<smiles></smiles><smiles></smiles>

Figure $1 \mid$ Formulas of the $\operatorname{Ir}(\mathrm{III})$ photosensitizers investigated in this work $\left(3: \mathrm{R}=\mathrm{H} ; 4: \mathrm{R}=\mathrm{CF}_{3} ; 5: \mathrm{R}=t\right.$-Bu). 

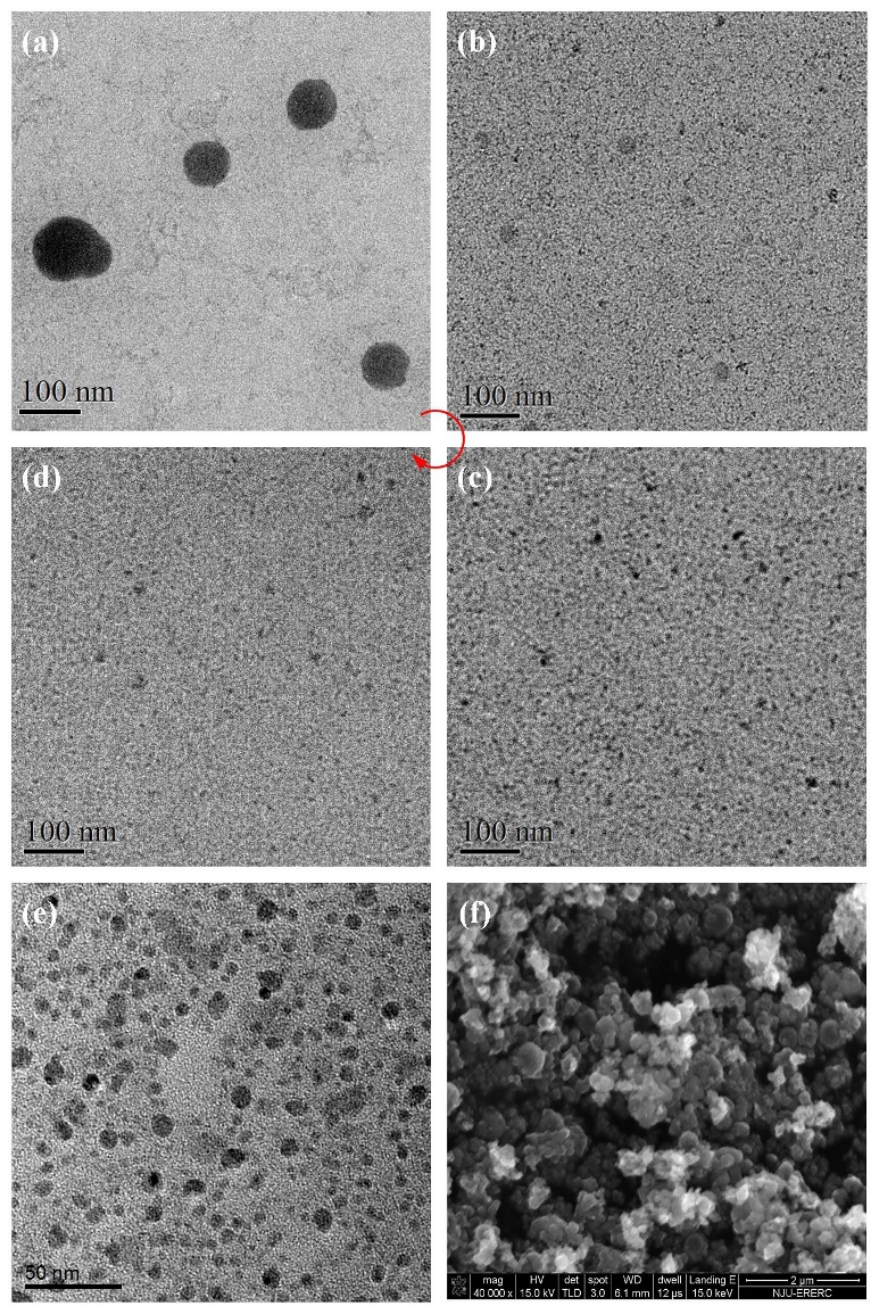

Figure 2 TEM images of $\mathrm{MoS}_{2}$ prepared in methanol with ratio of PVP (monomeric units) to $\mathrm{MoS}_{2}$ of 2.5 (a), 10 (b), 40 (c), 80 (d), 0 (e) and SEM image of $\mathrm{MoS}_{2}$ particles prepared in aqueous solution with ratio of PVP to $\mathrm{MoS}_{2}$ at 40 (f). The diameter and dispersion of the NPs improves as the ratio of PVP to $\mathrm{MoS}_{2}$ increases, as shown by the curved arrow.

particles unavoidably agglomerated into large ones. When the colloid preparation was conducted without PVP or in an aqueous solution with PVP, a $\mathrm{MoS}_{2}$ colloid failed to form, and the particle size of the prepared $\mathrm{MoS}_{2} \mathrm{NPs}$ was greater than $20 \mathrm{~nm}$, as shown in Figs. 2e and $2 \mathrm{f}$, respectively. Due to the relatively low contrast, the TEM micrographs do not provide an unambiguous NP diameter. However, the difference is clear and is expected to lead to a significant impact on their catalytic performance. The diffuse absorption spectrum of colloidal $\mathrm{MoS}_{2}$ in methanol is rather featureless (Fig. S3), which is consistent with that of the $\mathrm{MoS}_{2}$ colloids reported in the literature ${ }^{35}$.

All of the iridium complexes were successfully synthesized according to standard procedures and fully characterized. Various cyclometalating and ancillary ligands helped modulate the photophysical and electrochemical properties of the target light-harvesting complexes and provided further insight into the potential relationship between the substituents and the PS performance. In particular, the use of the $\mathrm{COOH}$ group in the ancillary ligand of 2,2' -bipyridine$4,4^{\prime}$-dicarboxylate $\left(\mathrm{H}_{2} \mathrm{bpdc}\right)$ was expected to control the funneling of excitation energy toward the photochemical reaction center. Among these iridium PSs, complexes 1 and 2 appear to be electrically neutral, with one of the carboxyl group losing its proton to become a negatively charged carboxylate group $\left(-\mathrm{COO}^{-}\right)^{36}$, while the other $\operatorname{Ir}(\mathrm{III})$ compounds were isolated as their hexafluorophosphate $\left(\mathrm{PF}_{6}^{-}\right)$salts.
Photophysical and electrochemical properties. The absorption and emission spectra of all of the Ir(III) complexes measured in a methanol solution at $278 \mathrm{~K}$ are shown in Fig. 3, and the data are summarized in Table 1. All of the complexes exhibit intense absorption bands in the UV region, which corresponds to the spin-allowed singlet ligand-centered $\left({ }^{1} \mathrm{LC}\right) \pi \rightarrow \pi^{*}$ transitions of both the $\mathrm{C}^{\wedge} \mathrm{N}$ and $\mathrm{N}^{\wedge} \mathrm{N}$ ligands. The less intense absorption features are observed in the visible region and are primarily attributed to metal-to-ligand charge transfer (MLCT), which may also include some ligand-to-ligand charge transfer ( ${ }^{1}$ LLCT). Upon excitation at $350 \mathrm{~nm}$, all of the complexes exhibit intense orange to green luminescence with decay lifetimes between 0.20 and $0.68 \mu \mathrm{s}$ (Fig. S4). To further elucidate the nature of the excited states, density functional theory (DFT) calculations were performed on all of the Ir(III) complexes. The contour plot of the frontier molecular orbitals is shown in Table S1. For all of the complexes, the highest occupied molecular orbitals (HOMOs) are distributed between the $\operatorname{Ir}(\mathrm{III})$ center and the $\pi$ orbitals of the cyclometalated ligands. In contrast, the lowest unoccupied molecular orbitals (LUMOs) are primarily localized on the ancillary bipyridine ligand with small contributions from the Ir orbitals, which is in agreement with the results from previous studies ${ }^{23,36}$. For 1 and 2 , the presence of the electronic densities of the LUMO on the anchoring units is believed to facilitate electron transfer from the excited complex to the catalytic reaction center (e.g., $\mathrm{MoS}_{2}$ ). These results also suggest that the excited states of all of the complexes are primarily due to the contribution of a mixture of ${ }^{3}$ MLCT $\left[\mathrm{d} \pi(\mathrm{Ir}) \rightarrow \pi^{*}{ }_{\mathrm{N}^{\wedge} \mathrm{N}}\right]$ and ${ }^{3}$ LLCT $\left(\pi_{\mathrm{C}^{\wedge} \mathrm{N}} \rightarrow \pi^{*}{ }_{\mathrm{N}^{\wedge} \mathrm{N}}\right)$ transitions.

The electrochemical behaviors of all of the Ir(III) complexes were measured using cyclic voltammetry in an acetonitrile solution, and the electrochemical data are presented in Table 1. All of the compounds exhibit an oxidation potential in the range of +1.02 to $+1.52 \mathrm{~V}$ (vs. $\mathrm{Ag} / \mathrm{AgCl}$ ) and a reduction couple at ca. -1.65 to $-1.21 \mathrm{~V}$ (vs. Ag/AgCl). Based on the compositions of the HOMOs and LUMOs, the oxidation process is related to a metal-aryl centered process for each complex, while the reduction occurs on the ancillary bipyridine ligand with little contribution from the iridium metal center, which was determined in the study on the related cyclometalated $\operatorname{Ir}(\mathrm{III})$ complexes.

The excited-state reduction potentials, $E\left(\mathrm{PS}^{*} / \mathrm{PS}^{-}\right)$, are obtained from $E\left(\mathrm{PS}^{*} / \mathrm{PS}^{-}\right)=E_{\text {red }}+E_{0-0}$, in which $E_{\text {red }}$ is the first reduction potential of $\operatorname{Ir}(\mathrm{III})$ compounds and $E_{0-0}$ is the zero-zero excitation energy obtained from the optical spectra. The calculated $E\left(\mathrm{PS}^{*} / \mathrm{PS}^{-}\right)$ values of the complexes, which range from +1.22 to $+1.56 \mathrm{~V}$ versus $\mathrm{NHE}$, are more positive than the oxidation potential of both ascorbic acid $\left(\mathrm{H}_{2} \mathrm{~A}\right)$ and triethanolamine (TEOA) suggesting that the electron transfer from the electron donor to the Ir(III) species via a reductive quenching pathway is thermodynamically feasible ${ }^{37,38}$. To confirm these analyses, quenching experiments were conducted in methanol/ water $(1: 1, \mathrm{v} / \mathrm{v})$ solutions of these Ir(III) complexes with the addition of quenchers. The excited state of all of the Ir(III) complexes were quenched by both $\mathrm{H}_{2} \mathrm{~A}$ and TEOA following Stern-Volmer plots (Fig. S5), and the quenching rate constants are summarized in Table S4.

Hydrogen production. Photocatalytic hydrogen production using a freshly prepared colloidal suspension of $\mathrm{MoS}_{2}$ NPs was initially operated in a methanol/water solution with iridium complex 1 as a PS and $\mathrm{H}_{2} \mathrm{~A}$ as a sacrificial reducing (SR) agent under visible light irradiation of the system. $\mathrm{No}_{2}$ formation was detected after $8 \mathrm{~h}$ of irradiation in the absence of one of the components (i.e., $\operatorname{Ir}(\mathrm{III}) \mathrm{PS}$, $\mathrm{MoS}_{2} \mathrm{NPs}$ WRC or $\mathrm{H}_{2} \mathrm{~A}$ ) or when the reaction was performed without irradiation. Optimization of the reaction medium for hydrogen production was performed in a reaction medium with various methanol-water volume ratios. The TON based on $\mathrm{MoS}_{2}$ increased from 60 to 211 as the ratio of methanol to water changed 

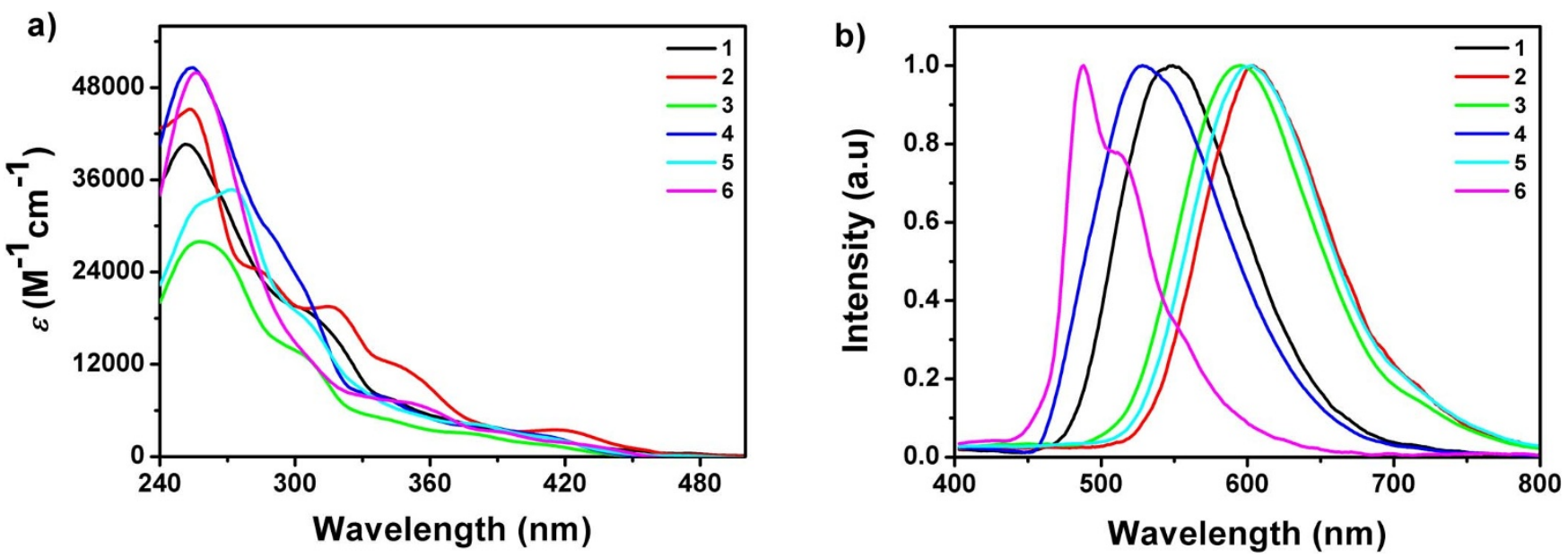

Figure $3 \mid$ (a) Absorption spectra and (b) normalized emission spectra of complexes 1-6 in methanol at room temperature.

from $1: 4$ to $1: 1(\mathrm{v} / \mathrm{v})$ (Entries 1 and 2 in Table 2$)$ while the other reaction conditions remained unchanged. A further increase in the ratio of methanol/water to $4: 1$ resulted in a decrease in the amount of hydrogen production to $114 \mathrm{H}_{2}$ TON based on $\mathrm{MoS}_{2}$ (Entry 3 in Table 2). The photochemical process involving intermolecular electron transfer is sensitive to changes in the lower dielectric constant of the reaction media. The highest catalytic efficiency was achieved in a 1:1 methanol-water solution, which could provide a balance between the benefit of the lower dielectric constant at higher methanol concentration and the need for water as a proton source for extracting hydrogen ${ }^{39}$. Under the condition of taking methanol as a reaction medium without water, the declined activity was observed with a TON of approximately 40 ; in this case, ascorbic acid can act as a source of protons.

As a hydrogen evolution catalyst, the activity of $\mathrm{MoS}_{2} \mathrm{NPs}$ is correlated with the number of unsaturated sulfur atoms on the edges of the $\mathrm{NPs}^{40}$, which enable them to absorb and release hydrogen. Therefore, the particle size and dispersion of the $\mathrm{MoS}_{2}$ NPs play a key role in its catalytic activity. In the present study, this factor was adjusted by varying the initial ratio of PVP to $\mathrm{MoS}_{2}$ toward the target. Fig. 4a shows the effect of the colloidal $\mathrm{MoS}_{2}$ NPs with various ratios of PVP to $\mathrm{MoS}_{2}$ on the hydrogen evolution efficiency using complex $1(20 \mu \mathrm{M})$ as the PS and $\mathrm{H}_{2} \mathrm{~A}$ as the electron donor under visible light irradiation $(\lambda>420 \mathrm{~nm})$. When the ratio of PVP/MoS 2 changes from 2.5 to 40 , the hydrogen evolution efficiency in the homogeneous-like system increased as the particle size of $\mathrm{MoS}_{2}$ decreased, which may be due to the presence of much more active sites due to the smaller size and better dispersion of the $\mathrm{MoS}_{2}$ NPs. In addition, the existence of PVP allows for the enhancement of energy transfer in the solarfuel converison ${ }^{41}$. The system with a $\mathrm{PVP} / \mathrm{MoS}_{2}$ ratio of 40 exhibits the highest activity for hydrogen production with a TON of 211 based on $\mathrm{MoS}_{2}$ NPs after $20 \mathrm{~h}$ of irradiation. Although a smaller diameter of $\mathrm{MoS}_{2}$ particles was observed for a $\mathrm{PVP} / \mathrm{MoS}_{2}$ ratio of 80 , a lower photocatalytic activity was observed, which may be due to the disruption of electron transfer between the PS and WRC affecting the photocatalytic reactions when a large number of PVP surround $\mathrm{MoS}_{2}$ in the reaction solution. When $\mathrm{MoS}_{2}$ NPs in the bulk powder form were used as a WRC in an heterogeneous system of $\mathrm{Ir}(\mathrm{III})-\mathrm{MoS}_{2}-\mathrm{H}_{2} \mathrm{~A}$, no $\mathrm{H}_{2}$ was detected suggesting that it is quite different from the NPs. Due to the size-dependent energy shift, the conduction band potential is not sufficiently large enough for bulk $\mathrm{MoS}_{2}$ to function as a catalyst to reduce protons ${ }^{42}$. In addition, when PVP was employed in place of the colloidal $\mathrm{MoS}_{2}$ NPs under identical conditions, hydrogen was not produced, which indicated that participation of PVP in the reaction can be ignored.

To gauge the effect of the concentrations of the PS and WRC, hydrogen production was conducted with various concentrations of $\mathrm{MoS}_{2}$ colloid or 1 when all of the other conditions remained constant. As shown in Fig. 4b, a substantial increase in hydrogen evolution with complex 1 was observed as the initial $\mathrm{MoS}_{2}$ concentration increased. For $\mathrm{MoS}_{2}$ NPs concentration of 5, 10, 20, 50 and $100 \mu \mathrm{M}$ in the presence of $100 \mu \mathrm{M}$ PS and $100 \mathrm{mM} \mathrm{H}_{2} \mathrm{~A}, 282,489$, 731,1290 and $1923 \mu \mathrm{mol}$ of $\mathrm{H}_{2}$ was obtained with the TON varying from 1128 to 384 based on $\mathrm{MoS}_{2}$ after $20 \mathrm{~h}$ of irradiation. Similarly, an increase in the total hydrogen yield with a fixed concentration of $\mathrm{MoS}_{2}$ NPs was also observed when the concentration of the added PS increased from $5 \mu \mathrm{M}$ to $100 \mu \mathrm{M}$. In addition, the TON increased from 82 to 731 based on $\mathrm{MoS}_{2}$ (Fig. 4c). Therefore, the concentration of both the WRC and PS are critical parameters that affect the catalytic production of hydrogen from water.

Table 1 | Photophysical and electrochemical data of Ir(III) complexes 1-6

\begin{tabular}{|c|c|c|c|c|c|c|c|c|}
\hline PS & $\lambda_{\mathrm{abs}}(\mathrm{nm})^{\mathrm{a}}$ & $\lambda_{\mathrm{em}}(\mathrm{nm})^{\mathrm{a}}$ & $E_{\mathrm{ox}}(\mathrm{V})^{\mathrm{b}}$ & $E_{\text {red }}(\mathrm{V})^{\mathrm{b}}$ & $E_{0-0}(e V)^{c}$ & $E\left(P S * / P S^{-}\right)(V)^{d}$ & $E\left(\mathrm{PS}^{+} / \mathrm{PS}^{*}\right)(\mathrm{V})^{\mathrm{d}}$ & $\tau(\mu s)^{e}$ \\
\hline 1 & 251,344 & 549 & 1.49 & -1.12 & 2.58 & 1.46 & -1.09 & 0.68 \\
\hline 2 & 253,350 & 604 & 1.22 & -1.12 & 2.34 & 1.22 & -1.12 & 0.54 \\
\hline 3 & 258,379 & 595 & 1.44 & -1.01 & 2.41 & 1.40 & -0.97 & 0.29 \\
\hline 4 & 254,342 & 528 & 1.72 & -1.11 & 2.67 & 1.56 & -0.95 & 0.33 \\
\hline 5 & 271,381 & 603 & 1.33 & -1.10 & 2.37 & 1.27 & -1.04 & 0.20 \\
\hline 6 & 259,354 & 488 & 1.25 & -1.45 & 2.73 & 1.28 & -1.48 & 0.27 \\
\hline \multicolumn{9}{|c|}{ 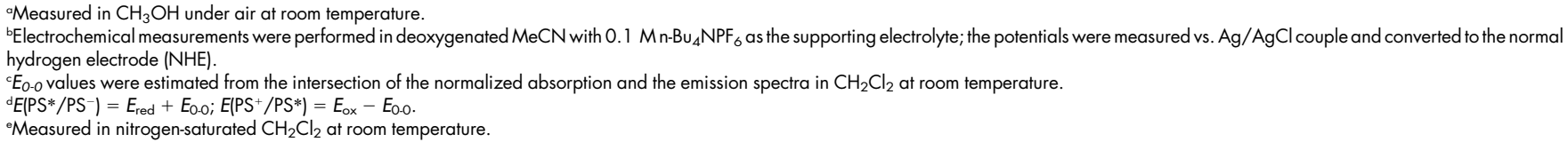 } \\
\hline
\end{tabular}


Table 2 | Photoinduced hydrogen evolution with $\operatorname{Ir}($ III) complexes $1-6^{a}$

\begin{tabular}{llcc} 
Entry & \multicolumn{1}{c}{ PS } & Methanol/Water & TON $^{\mathrm{b}}$ (TON*) $^{\mathrm{b}}$ \\
\hline 1 & $\mathbf{1}(20 \mu \mathrm{M})$ & $1: 4$ & 60 \\
2 & $\mathbf{1}(20 \mu \mathrm{M})$ & $1: 1$ & 211 \\
3 & $\mathbf{1}(20 \mu \mathrm{M})$ & $4: 1$ & 114 \\
4 & $\mathbf{1}(100 \mu \mathrm{M})$ & $1: 1$ & $731(1421)$ \\
5 & $\mathbf{2}(100 \mu \mathrm{M})$ & $1: 1$ & $426(623)$ \\
6 & $\mathbf{3}(100 \mu \mathrm{M})$ & $1: 1$ & $4(12)$ \\
7 & $\mathbf{4}(100 \mu \mathrm{M})$ & $1: 1$ & $3(15)$ \\
8 & $\mathbf{5}(100 \mu \mathrm{M})$ & $1: 1$ & $3(9)$ \\
9 & $\mathbf{6}(100 \mu \mathrm{M})$ & $1: 1$ & $8(10)$ \\
10 & {$[\text { Ir(ppy) } 2(\mathrm{bpy})]^{+}(100 \mu \mathrm{M})$} & $1: 1$ & 48 \\
11 & {$[\text { Ru(dmphen) }]^{2+}(100 \mu \mathrm{M})$} & $1: 1$ & 92 \\
\hline
\end{tabular}

oReactions contained $20 \mu \mathrm{M} \mathrm{MoS}_{2} \mathrm{NPs}$ and $100 \mathrm{mM}\left[\mathrm{H}_{2} \mathrm{~A}\right]$ in a $100 \mathrm{~mL}$ solution under $20 \mathrm{~h}$ of irradiation; irradiation $\lambda>420 \mathrm{~nm}$.

bTON was calculated based on the catalyst. TON* was obtained from that with TEOA as a

sacrificial electron donor instead of $\mathrm{H}_{2} \mathrm{~A}$. In the presence of TEOA, the $\mathrm{pH}$ was adjusted to 7.0 by addition of $\mathrm{HCl}$ to the catalytic solution.

The performance of colloidal $\mathrm{MoS}_{2}$ as a WRC for hydrogen photoproduction was evaluated in comparison to other WRCs, such as colloidal platinum generated in situ from $\mathrm{K}_{2} \mathrm{PtCl}_{4}$, $\left[\mathrm{Co}(\mathrm{bpy})_{3}\right] \mathrm{Cl}_{2}$, $\left[\mathrm{Co}(\mathrm{dmgH})_{2}\left(\mathrm{H}_{2} \mathrm{O}\right)_{2}\right]\left(\mathrm{dmgH}_{2}=\right.$ dimethylglyoxime $)$ or $[\mathrm{Rh}(\mathrm{dtb}-$ bpy $\left.)_{3}\right]\left(\mathrm{PF}_{6}\right)_{3}$ (dtb-bpy $=4,4^{\prime}$-di-tert-butyl-2,2' -bipyridine), in
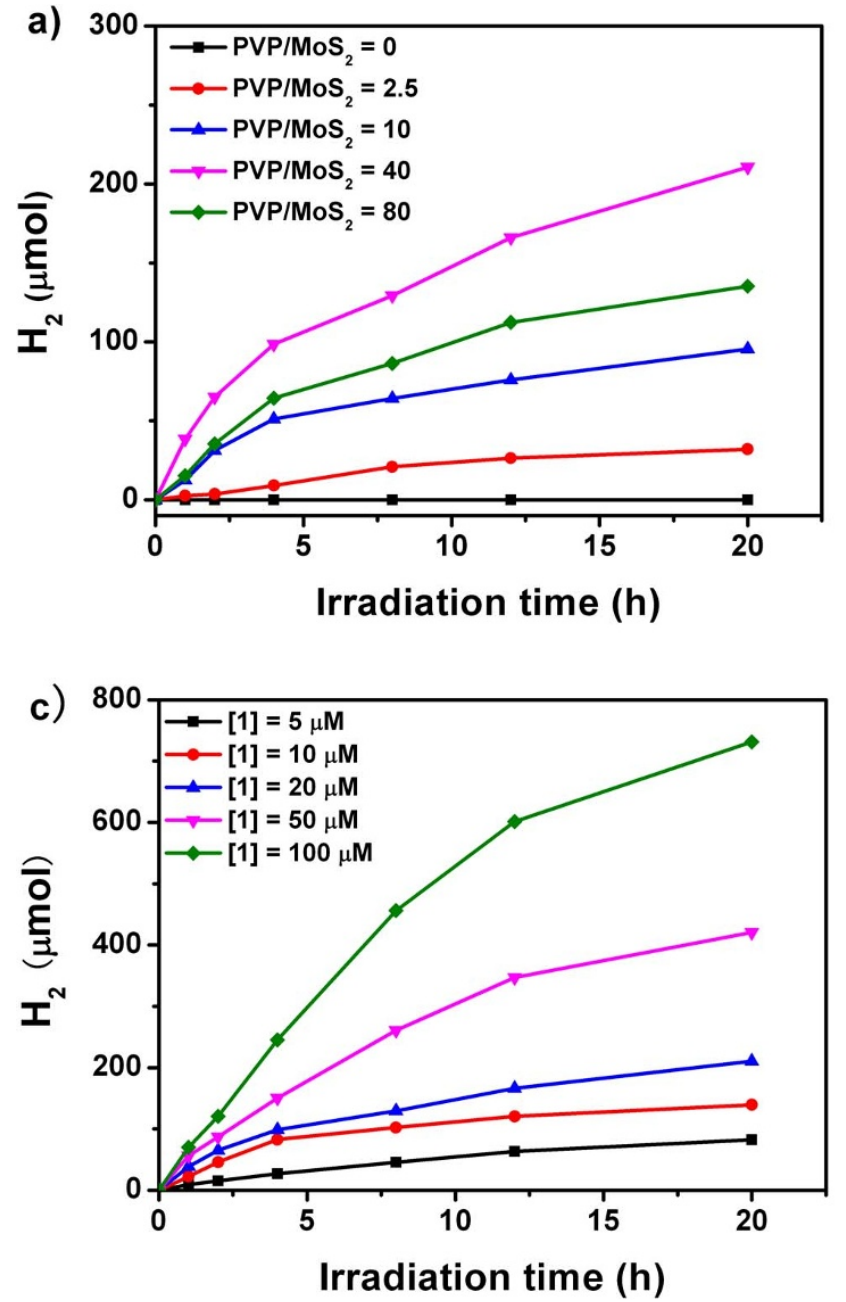

association with 1 under irradiation for $20 \mathrm{~h}$ and the same experimental conditions. As shown in Fig. 4d, the TONs based on these species are quite low. The Rh WRC is more active with 30 TON obtained after a $20 \mathrm{~h}$ of irradiation. With colloidal $\mathrm{MoS}_{2} \mathrm{NPs}$, a more than ten-fold enhancement compared to the Pt catalyst was observed, and hydrogen production slowed down but still retained some activity after the cessation of the reaction (after $20 \mathrm{~h}$ ), which observed in the kinetics plots in Figs. $4 \mathrm{a}-\mathrm{c}$. With the other WRCs due to their poor stability, the reactions lasted approximately 8-12 h. In particular, colloidal platinum easily agglomerates in the presence of methanol as demonstrated by the observation of the formation of $\mathrm{Pt}$ particles as a black particulate matter during irradiation. Therefore, the dispersed $\mathrm{MoS}_{2}$ NPs exhibited considerable durability and significantly greater catalytic activity than commonly utilized WRCs for hydrogen production, which may be due to more efficient charge transfer occurring within the cooperative components of the photochemical reactions.

After approximately $20 \mathrm{~h}$ of irradiation, the hydrogen-evolution activity decreased sharply due to the decomposition of at least one component of the $\mathrm{Ir}$ (III) PS and $\mathrm{MoS}_{2}$ NPs in the presence of a large excess of $\mathrm{H}_{2} \mathrm{~A}$. To confirm this decomposition, the PS or catalyst were re-added when the $\mathrm{H}_{2}$ evolution ceased. When the $\mathrm{MoS}_{2} \mathrm{NPs}$ were re-added to the reaction solution, only $16.5 \mu \mathrm{mol} \mathrm{H}_{2}$ was regenerated after another $20 \mathrm{~h}$ of irradiation, whereas the parallel experiment showed that the re-addition of Ir(III) PS resulted in substantial
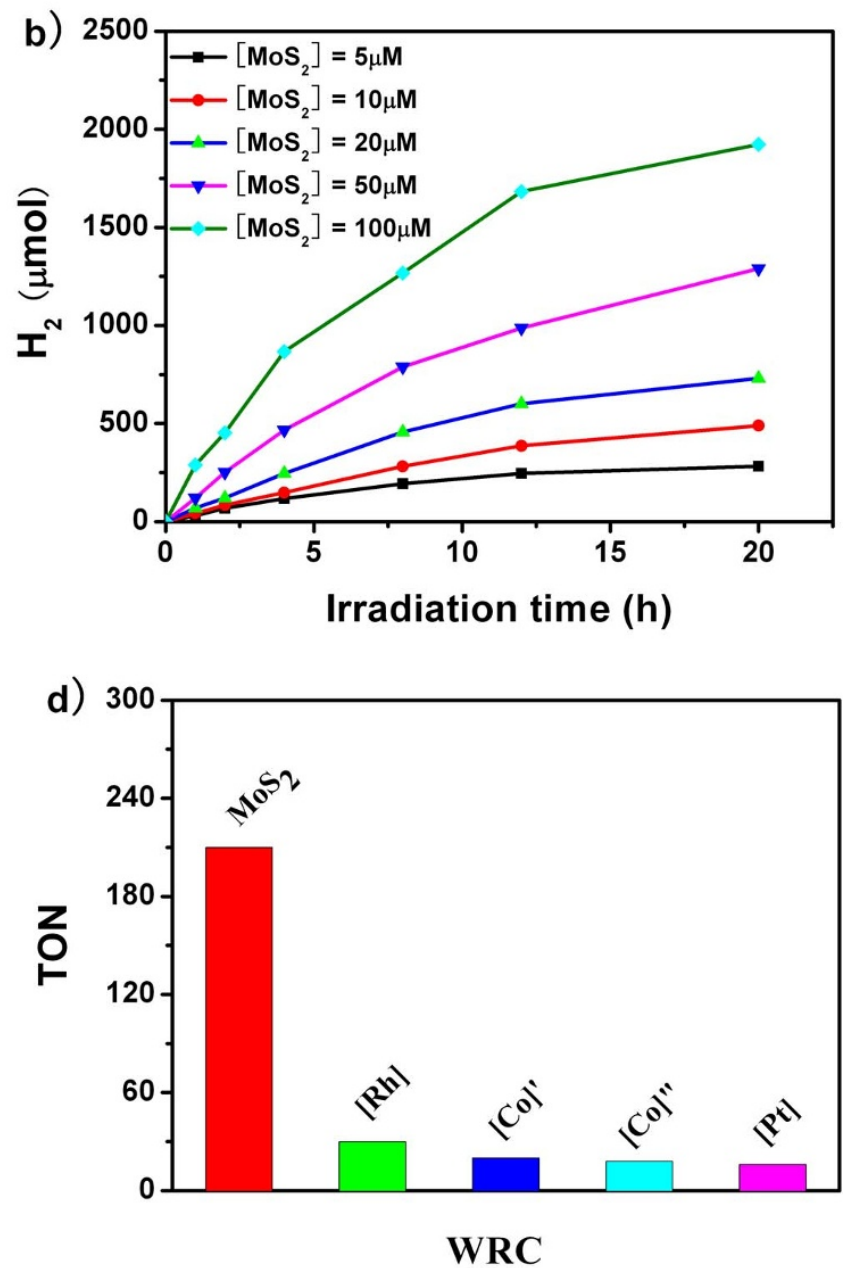

Figure 4 Hydrogen production using (a) varying ratios of PVP to $\mathrm{MoS}_{2}$ with $20 \mu \mathrm{M} 1$ and $20 \mu \mathrm{M} \mathrm{MoS}_{2}$; (b) varying the concentration of colloidal MoS NPs with $100 \mu \mathrm{M} \mathrm{1;} \mathrm{(c)} \mathrm{varying} \mathrm{the} \mathrm{concentration} \mathrm{of} 1$ with $20 \mu \mathrm{M} \mathrm{MoS}_{2} \mathrm{NPs}$; (d) $20 \mu \mathrm{M} 1$ and a $20 \mu \mathrm{M}$ concentration of various WRC. WRC: [Rh] = $\left[\mathrm{Rh}(\mathrm{dtb}-\mathrm{bpy})_{3}\right]\left(\mathrm{PF}_{6}\right)_{3},[\mathrm{Co}]^{\prime}=\left[\mathrm{Co}(\mathrm{bpy})_{3}\right] \mathrm{Cl}_{2},[\mathrm{Co}]^{\prime \prime}=\left[\mathrm{Co}(\mathrm{dmgH})_{2}\left(\mathrm{H}_{2} \mathrm{O}\right)_{2}\right]$ and $[\mathrm{Pt}]=\mathrm{K}_{2} \mathrm{PtCl}_{4}$. All of the reactions were studied in $1: 1(\mathrm{v} / \mathrm{v})$ methanol-water media $(100 \mathrm{~mL})$ in the presence of $100 \mathrm{mM} \mathrm{H}_{2} \mathrm{~A}$ at $\mathrm{pH} 6.5(\lambda>420 \mathrm{~nm})$. Here, the pH value was not optimized. 


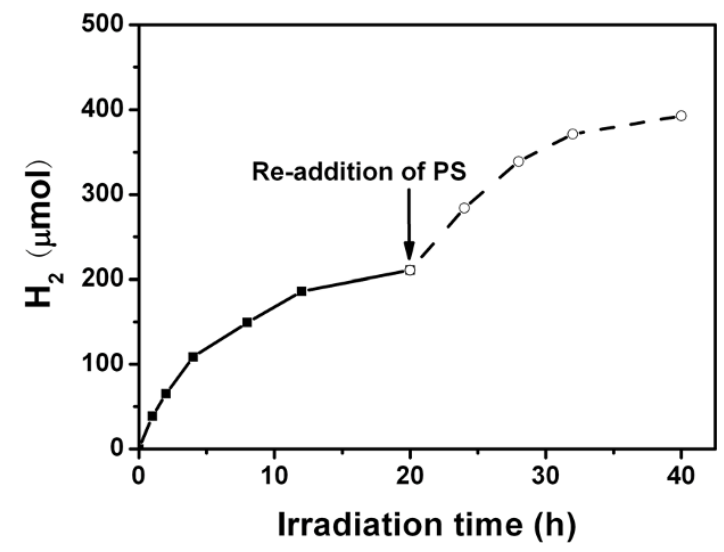

Figure $5 \mid \mathrm{H}_{2}$ production as a function of time showing the stability of the system with re-addition of 1 after $20 \mathrm{~h}$ of irradiation $(\lambda>420 \mathrm{~nm})$. The experiment was performed in $1: 1(\mathrm{v} / \mathrm{v})$ methanol-water media $(100 \mathrm{~mL})$ in the presence of $20 \mu \mathrm{M} \mathrm{1}, 20 \mu \mathrm{M} \mathrm{MoS}_{2}$ and $100 \mathrm{mM} \mathrm{H}_{2} \mathrm{~A}$ at the original $\mathrm{pH}$ of 6.5 .

recovery of catalytic activity, as shown in Fig. 5. These results clearly indicated that the $\mathrm{MoS}_{2}$ NPs were stable during the reaction. After the $\mathrm{H}_{2}$ production leveled off in this system, the decomposition products were extracted from the reaction mixture and characterized by gas chromatography-mass spectrometry (GC-MS). There was a strong ion appearing at $m / z=223$, which was characteristic of the 2(4-trifluoromeththylphenyl)pyridine that dissociated from complex 1 after the photocatalytic reaction (Fig. S6). The result further confirmed that the decomposition of the PS may account for the cessation of the activity of the reaction system.

Based on the aforementioned results, the use of and electrondonating agent, such as triethanolamine (TEOA), instead of $\mathrm{H}_{2} \mathrm{~A}$ was investigated in the multicomponent photocatalytic water reduction systems (at a favorable $\mathrm{pH}$ of 7.0) (Entry 4 in Table 2). A much higher TON of 1421 based on the catalyst ( $\left.20 \mu \mathrm{M} \mathrm{MoS}_{2} \mathrm{NPs}\right)$ was obtained after $12 \mathrm{~h}$ of irradiation compared to that of $\mathrm{H}_{2} \mathrm{~A}$, which had a $\mathrm{H}_{2}$ TON of 731 after $20 \mathrm{~h}$ of irradiation under the same conditions. In addition, the turnover number frequency (TOF) with TEOA was as high as $118 \mathrm{~h}^{-1}$, which is higher than that of $\mathrm{H}_{2} \mathrm{~A}$ (i.e., TOF of $\mathrm{H}_{2} \mathrm{~A}$ was $37 \mathrm{~h}^{-1}$ ). It should be noted that the lifetime of the $\mathrm{H}_{2}$ evolution system with TEOA was relatively short where $87 \%$ of the total hydrogen was evolved during the first four hours. Under the same conditions using TEOA during the course of a $12 \mathrm{~h}$ experiment, the TON reached a maximum value of approximately

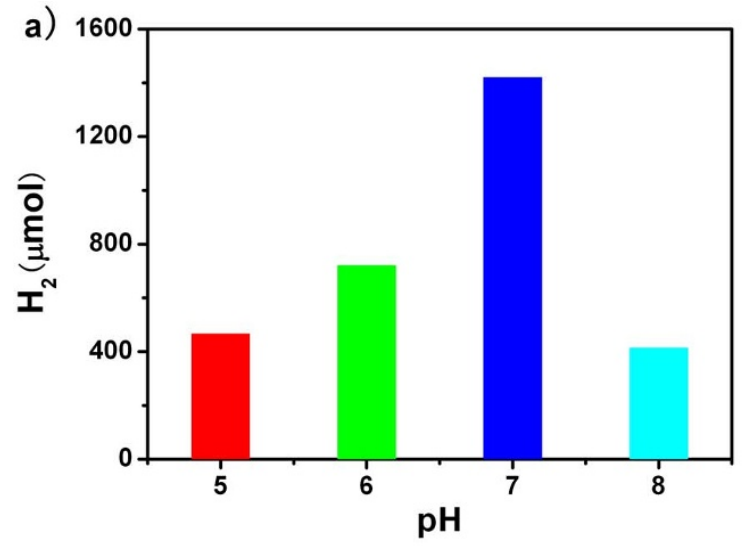

3124 at concentrations of $\mathrm{MoS}_{2}$ NPs down to $1 \mu \mathrm{M}$. While $\mathrm{H}_{2} \mathrm{~A}$ quenched the excited state of 1 more efficiently than TEOA, $\mathrm{H}_{2} \mathrm{~A}$ was more readily oxidized than TEOA and less effective than TEOA in performing the reaction. This result is most likely due to the $\mathrm{pH}$ of the reaction with TEOA under optimized reaction conditions. The photocatalytic performance is closely related to the $\mathrm{pH}$ value of the reaction system. The effect of $\mathrm{pH}$ on the production of $\mathrm{H}_{2}$ was investigated in the 1-MoS 2 -TEOA systems, as shown in Fig. 6a. Maximum production of $\mathrm{H}_{2}$ occurred at a $\mathrm{pH}$ of 7 , which is consistent with the observations in related photocatalytic systems. In addition, the apparent quantum yield (AQY) in the $1-\mathrm{MoS}_{2}$-TEOA system was determined to evaluate the photon-to- $\mathrm{H}_{2}$ efficiency under irradiation of monochromatized light at 350, 380, 400, 420, 440 and $480 \mathrm{~nm}$ under the given reaction conditions. A maximum AQY of $12.4 \%$ was obtained under irradiation at $400 \mathrm{~nm}$ (light intensity: $0.40 \mathrm{~mW} / \mathrm{cm}^{2}$ ). This value compares favorably with other iridiumbased multicomponent systems for the photogeneration of hydrogen using colloidal Pt as the catalyst ${ }^{19,20}$. As shown in Fig. 6b, the AQY as a function of the increasing wavelength is in agreement with the characteristic features of the excitation spectra of compound 1 (Fig. S7), which indicates that the occurrence of hydrogen evolution reaction was plausibly governed by the excited state of 1 .

\section{Discussion}

The contribution from the system based on colloidal $\mathrm{MoS}_{2} \mathrm{NPs}$ as the catalyst with an iridium sensitizer for photoinduced $\mathrm{H}_{2}$ production was impressive based on the aforementioned results. The size and dispersion of the $\mathrm{MoS}_{2}$ NPs has an obvious effect on the improvement of the catalytic performance in photocatalytic $\mathrm{H}_{2}$ production. The amount of unsaturated sulfur atoms, which reside on the $\mathrm{MoS}_{2}$ NPs edges and are responsible for the high catalytic activity, increases as the particle size decreases, resulting in better dispersion and increased catalytic activity. In addition, the ability to perform as an active site is controlled by the value of the band gap in the nanoscale $\mathrm{MoS}_{2}$ due to quantum size effects ${ }^{42}$, as shown in supplementary Fig. S8. The reduction potential of the $\mathrm{MoS}_{2}$ NPs shifts to more negative values as the size of the $\mathrm{MoS}_{2}$ particle decreases, which offers the potential for proton reduction at an appreciable rate. However, the conduction band value of bulk $\mathrm{MoS}_{2}$ is more positive than the proton reduction potential $E\left(\mathrm{H}^{+} / \mathrm{H}_{2}\right)$ making bulk $\mathrm{MoS}_{2}$ inactive for the formation of hydrogen.

The photocatalytic reaction in the multicomponent system involves electron transfer, which proceeds either by oxidative or reductive quenching. To determine which quenching is operative in the reaction described here, fluorescence quenching within the PS, the WRC and SR agent must be investigated. In this study, the

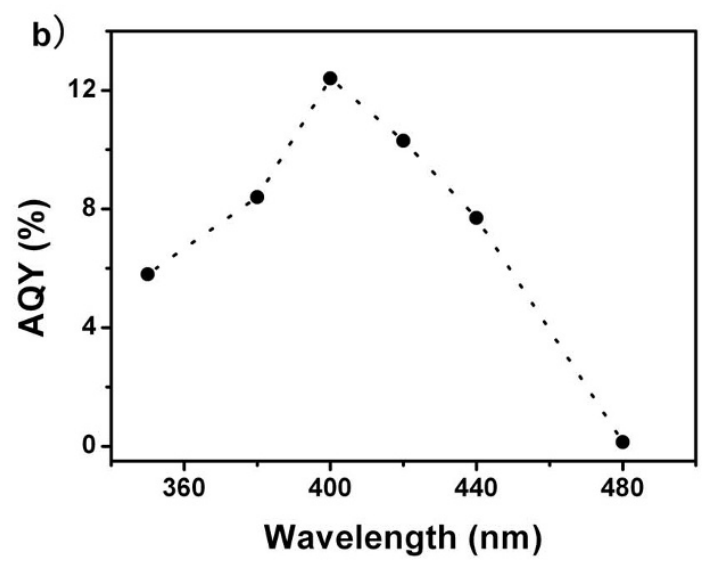

Figure 6 (a) Hydrogen production as a function of $\mathrm{pH}$ in the $1-\mathrm{MoS}_{2}$-TEOA systems. $\mathrm{HCl}$ (approximately $38 \%$ ) was added to each solution to adjust the $\mathrm{pH}$. (b) Hydrogen production quantum yield plotted as a function of the wavelength of the incident light in systems with TEOA at $\mathrm{pH} 7 \mathrm{after}$ initial $4 \mathrm{~h}$ of irradiation. 
excited state (PS*) of complex 1 was substantially quenched by both $\mathrm{H}_{2} \mathrm{~A}$ and TEOA. However, the contribution of the WRC of $\mathrm{MoS}_{2}$ to the quenching processes was difficult to estimate due to the optical properties of $\mathrm{MoS}_{2}$. In these $\mathrm{MoS}_{2}$-based systems, the amount of the SR agent is more than 1000 times that of the catalyst. The predominant pathway for electron transfer was proposed to proceed via reductive quenching derived from the rapid oxidation of $\mathrm{H}_{2} \mathrm{~A}$ or TEOA combined with the strong oxidizing nature of the excited state of the PS. Previous studies have shown that the excited state of a neutral iridium complex ${ }^{27}$ (i.e., $\operatorname{Ir}\left(\right.$ ppy) ${ }_{3}$ (ppy $=2$-phenylpyridine)) cannot be quenched reductively by TEOA but can be oxidatively quenched by $\left[\mathrm{Co}(\mathrm{bpy})_{3}\right]^{2+}$. Under conditions identical to those used for hydrogen production by 1 , hydrogen was not produced by the $\operatorname{Ir}(\mathrm{ppy})_{3}-\mathrm{MoS}_{2}-\mathrm{H}_{2} \mathrm{~A}$ system under $12 \mathrm{~h}$ of visible light irradiation, which indicated that the electron was not transferred from the PS* to the catalyst, resulting in suppression in the production of hydrogen. Therefore, the reductive quenching pathway appears to be consistent with the results reported here for the photochemical system catalyzed by $\mathrm{MoS}_{2}$ NPs. In the hydrogen formation process, sensitizer 1 harvests visible light, and the excited state of the sensitizer is reductively quenched by the SR agent $\left(\mathrm{H}_{2} \mathrm{~A}\right)$ to generate the activated reduced iridium species that directly delivers reducing equivalents to the $\mathrm{MoS}_{2}$ NPs WRC where hydrogen is evolved.

Using adsorbing moieties, the sensitizer might be localized on the semiconductor nanoparticles to improve the electron transfer efficiency, which has been extensively employed in dye-sensitized solar cells $^{43,44}$. The Fourier transform IR (FT-IR) spectroscopy was used for extracting information of the binding of PS 1 on the $\mathrm{MoS}_{2} \mathrm{NPs}$ surface (Fig. S9). Two strong bands in the FT-IR spectrum of 1 appeared at approximately $1608 \mathrm{~cm}^{-1}$ and $1373 \mathrm{~cm}^{-1}$ corresponding to the asymmetric and symmetric stretch modes of the carboxylate group, respectively. For comparison of the characteristic peaks associated with the carboxylate group, the 1-sensitized $\mathrm{MoS}_{2} \mathrm{NPs}$ as a powder with diameters up to $20 \mathrm{~nm}$ was investigated; in the case of the colloidal $\mathrm{MoS}_{2}$ NPs, the IR bands involving the PVP were superimposed over the relevant peaks. Due to the interaction between PS 1 and the $\mathrm{MoS}_{2}$ NPs, the corresponding peaks in the adsorbed state occurred at $1602 \mathrm{~cm}^{-1}$ and $1402 \mathrm{~cm}^{-1}$. Based on spectral changes and the difference between the symmetric and asymmetric bands of the carboxylate group, the binding of the carboxylate groups of PS 1 on the $\mathrm{MoS}_{2}$ NPs surface was probably via a bridging bidentate mode ${ }^{45}$. The emission spectrum of PS 1 adsorbed on $\mathrm{MoS}_{2} \mathrm{NPs}$ was similar with that of 1 in $\mathrm{CH}_{2} \mathrm{Cl}_{2}$ solution (Fig. S10); however, the Ir-based emissions were not detected when using other Ir(III) complexes with other substituents such as $\mathbf{3}$ or $\mathbf{6}$ as a PS for sensitizing the $\mathrm{MoS}_{2}$ NPs. The photoluminescence studies provide a supplementary evidence of chemical interaction between 1 and the $\mathrm{MoS}_{2}$ NPs. Inspired by this possibility, the use of carboxylate groups on iridium sensitizer 1 was expected to promote charge transfer to the catalyst resulting in improved performance of the hydrogen evolution systems. After the successful application of complex 1, complex 2 bearing a $\mathrm{H}_{2}$ bpdc ligand with structure similar to 1 was evaluated. As expected, when $\mathrm{H}_{2} \mathrm{~A}$ was used as the SR agent, complex 2 also exhibited efficient activity with a $426 \mathrm{H}_{2}$ TON based on $\mathrm{MoS}_{2}$ for hydrogen production, which was lower than that observed for complex 1 (Entry 5 in Table 2). This result is due to a smaller quenching rate constant for $\mathrm{H}_{2} \mathrm{~A}$ and a shorter excited-state lifetime of 2 relative to 1 . To further address the relationship between the performance of the photocatalytic reaction and the structure of the sensitizer, other Ir(III) complexes (3-6) with other substituents, such as $-\mathrm{CH}_{2} \mathrm{OH}$ or $-\mathrm{NH}_{2}$ (see Fig. 1), which allow for structural analogues of complexes 1 and 2, were examined as PSs for hydrogen evolution under the same conditions. Only 4, 3, 3 and 8 TON based on $\mathrm{MoS}_{2}$ were observed after $20 \mathrm{~h}$ of irradiation for systems based on complexes 3, 4, 5 and 6 (Entries 6, 7, 8 and 9 in Table 2), respectively. In addition, the parent chromophore $\left[\operatorname{Ir}(\mathrm{ppy})_{2}(\mathrm{bpy})\right]^{+}$was also used as a reference PS. The unbound chromophore $\left[\operatorname{Ir}(\text { ppy })_{2}(\text { bpy })\right]^{+}$does not possess a moiety in the pendent groups eliminating the possibility of direct interaction between the PS and the WRC similar to complexes 1 and 2, and 48 TON based on $\mathrm{MoS}_{2}$ was observed

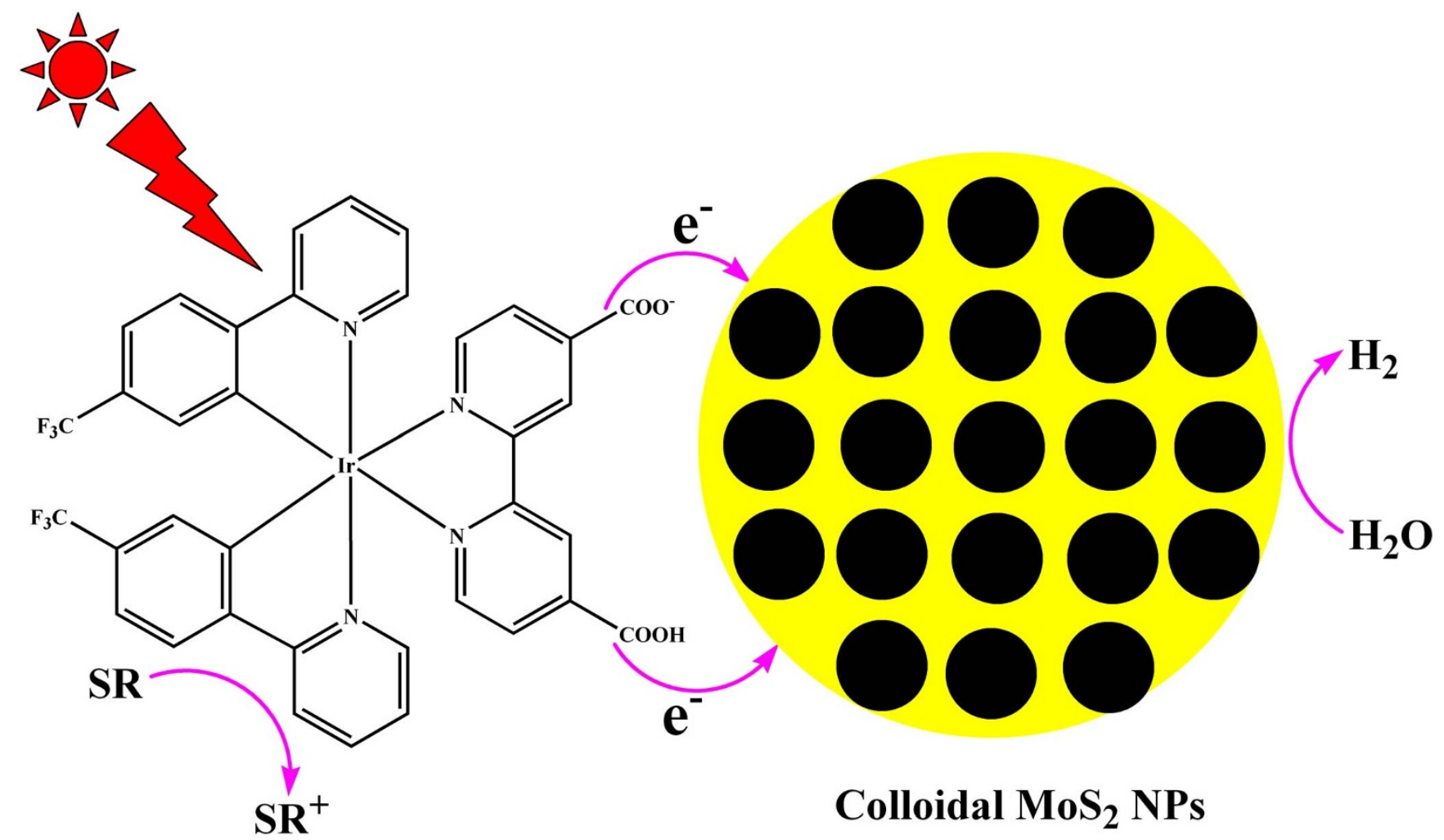

Figure $7 \mid$ Schematic representation of the electron transfer from PS 1 to the $\mathrm{MoS}_{2}$ NPs. 
(Entries 10 in Table 2). A "standard" PS of $\left[\mathrm{Ru}(\mathrm{dmphen})_{3}\right]\left(\mathrm{PF}_{6}\right)_{2}$ (dmphen $=4,7$-dimethy-1,10- phenanthroline) was used under the same conditions (Entry 11 in Table 2), and only $92 \mu \mathrm{mol}$ of $\mathrm{H}_{2}$ with respect to $\mathrm{MoS}_{2}$ was observed, which is comparable to the reported data using $\left[\mathrm{Ru}(\mathrm{bpy})_{3}\right]^{2+}$. The performance of these iridium PSs were also investigated using TEOA as a SR agent, and TONs of 12, 15, 9 and 10 were observed after $12 \mathrm{~h}$ of irradiation for system based on complexes $2,3,4,5$ and 6 , respectively, which are much less than those of complexes 1 and 2 .

Hydrogen is formed by photoinduced electron transfer. However, the contribution of this process to the reaction is not completely understood. In this study, the photophysical properties and the electrochemical behaviors of PSs are similar but result in completely different catalytic properties. It has been proposed that the electron transfer rates between the molecular PS and the WRC play an important role in determining the overall hydrogen evolution efficiency. In previous reports, the weak adsorption effects between iridium PSs and platinum from the vinyl or pendant pyridyl functionalities can not only facilitate fast ${ }^{25}$, directional electron transfer from the PS to the WRC but also effectively suppress the probability of bipyridyl photodissociation resulting in highly efficient activities for light-driven water reduction systems ${ }^{10}$. Studies on dye-sensitized $\mathrm{MoS}_{2}$ NPs with improved photoelectrochemical property are rare. However, a previous study has suggested that electron injection can occur when $\mathrm{Ru}\left(4,4^{\prime} \text {-dicarboxy-2,2' -bipyridine }\right)_{2}$ cis $(\mathrm{NCS})_{2}$ is adsorbed on the $\mathrm{MoS}_{2}$ nanoclusters via the carboxylate groups ${ }^{46}$. In this study, the photocatalytic results confirmed the existence of carboxylate groups by which electron can easily transfer from the adsorbing PS to the $\mathrm{MoS}_{2} \mathrm{NPs}$, as shown in Fig. 7. Ease of electron transfer is extremely important in determining the enhancement of the PS performance for hydrogen production. For complexes 1 and 2, the DFT results indicated that the electron resides on the side of the $\mathrm{COOH}$ moiety upon excitation. The electron might be easier to transfer to the $\mathrm{MoS}_{2} \mathrm{NPs}$ via $\mathrm{COOH}$, which may provide the active electron transfer channel. In contrast, the non-adsorbing PS may exhibit little or no attachment to the same catalyst in the colloidal $\mathrm{MoS}_{2}$ NPs leading to a lower photocatalytic activity.

In summary, molybdenum disulfide is an interesting hydrogen evolution catalyst because it is composed of more abundant and economical materials than are Pt-based catalysts. The utility of colloidal $\mathrm{MoS}_{2}$ as a catalyst coupled with iridium sensitizers for efficient photoinduced hydrogen production was developed using a threecomponent systems. The combined system exhibited much better catalytic activity than that observed for the $\mathrm{K}_{2} \mathrm{PtCl}_{4},\left[\mathrm{Co}(\mathrm{bpy})_{3}\right] \mathrm{Cl}_{2}$, $\left[\mathrm{Rh}(\mathrm{dtb}-\mathrm{bpy})_{3}\right]\left(\mathrm{PF}_{6}\right)_{3}$ and $\left[\mathrm{Co}(\mathrm{dmgH})_{2}\left(\mathrm{H}_{2} \mathrm{O}\right)_{2}\right]$ catalysts under identical conditions. Due to cooperative effects, the conversion efficiency reached $12.4 \%$ at $400 \mathrm{~nm}$ in the $\mathrm{Ir}(\mathrm{III})-\mathrm{MoS}_{2}$-TEOA system. For Ir(III) sensitizers, the substituent groups in the ancillary ligand were determined to influence their catalytic performance. The use of carboxylate groups leads to the formation of electron transfer channels promoting an increase in the electron transfer from the sensitizers to the colloidal $\mathrm{MoS}_{2} \mathrm{NPs}$, which positively affects the activity of the catalytic system. We anticipate that this study will provide new insights into producing a robust photochemical system with an improved conversion efficiency, and we believe that the promising $\mathrm{MoS}_{2}$ NPs-supported catalysts has the potential for use in a hybrid energy conversion system without the use of noble-metal complexes.

\section{Methods}

Syntheses. All of the iridium complexes (1-6) were prepared via the known two-step bridge-splitting procedure. The colloidal $\mathrm{MoS}_{2} \mathrm{NPs}$ were prepared via a one-step reaction of $\left(\mathrm{NH}_{4}\right)_{2} \mathrm{MoS}_{4}$ and hydrazine hydrate in a methanol solution according to a previously reported method.

Photogeneration of hydrogen experiments. The reactions were performed in a Pyrex vessel attached to a closed gas-circulation glass system and an evacuation system. The samples contained different concentrations of the PS, WRC and SR agent in a $100 \mathrm{~mL}$ mixed methanol-water solution with gentle magnetic stirring during the
$\mathrm{H}_{2}$ production experiments. The system was well-evacuated and subsequently backfilled with argon prior to side visible-light irradiation using a 300 W Xenon lamp equipped with a cut-off filter (radiation wavelength $>420 \mathrm{~nm}$ ). The evolved gases were periodically monitored in situ using an online gas chromatograph with a thermal conductivity detector (Shimadzu GC-8A, argon as a carrier gas and MS-5A column).

1. Lewis, N. S. \& Nocera, D. G. Powering the planet: chemical challenges in solar energy utilization. Proc. Natl. Acad. Sci. USA 103, 15729-15735 (2006).

2. Sun, L., Hammarström, L., Åkermark, B. \& Styring, S. Towards artificial photosynthesis: ruthenium-manganese chemistry for energy production. Chem. Soc. Rev. 30, 36-49 (2001).

3. Frischmann, P. D., Mahata, K. \& Würthner, F. Powering the future of molecular artificial photosynthesis with light-harvesting metallosupramolecular dye assemblies. Chem. Soc. Rev. 42, 1847-1870 (2013).

4. Han, Z. J., Qiu, F., Eisenberg, R., Holland, P. L. \& Krauss, T. D. Robust photogeneration of $\mathrm{H}_{2}$ in water using semiconductor nanocrystals and a nickel catalyst. Science 338, 1321-1324 (2012).

5. Matt, B. et al. Charge photo-accumulation and photocatalytic hydrogen evolution under visible light at an iridium(III)-photosensitized polyoxotungstate. Energy Environ. Sci. 6, 1504-1508 (2013).

6. Elvington, M., Brown, J., Arachchige, S. M. \& Brewer, K. J. Photocatalytic hydrogen production from water employing a Ru, Rh, Ru molecular device for photoinitiated electron collection. J. Am. Chem. Soc. 129, 10644-10645 (2007).

7. Martis, M., Mori, K., Kato, K., Sankar, G. \& Yamashita, H. What are the active species in the photoinduced $\mathrm{H}_{2}$ production with terpyridyl $\mathrm{Pt}(\mathrm{II})$ complexes? an investigation by in situ XAFS. ChemPhysChem 14, 1122-1125 (2013).

8. Sun, Y. J., Sun, J. W., Long, J. R., Yang, P. D. \& Chang, C. J. Photocatalytic generation of hydrogen from water using a cobalt pentapyridine complex in combination with molecular and semiconductor nanowire photosensitizers. Chem. Sci. 4, 118-124 (2013).

9. Yuan, Y. J. et al. Impact of ligand modification on hydrogen photogeneration and light-harvesting applications using cyclometalated iridium complexes. Inorg. Chem. 51, 4123-4133 (2012).

10. DiSalle, B. F. \& Bernhard, S. Orchestrated photocatalytic water reduction using surface-adsorbing iridium photosensitizers. J. Am. Chem. Soc. 133, 11819-11821 (2011).

11. Khnayzer, R. S. et al. Photocatalytic hydrogen production at titania-supported Pt nanoclusters that are derived from surface-anchored molecular precursors. J. Phys. Chem. C 116, 1429-1438 (2012).

12. Sakai, T., Mersch, D. \& Reisner, E. Photocatalytic hydrogen evolution with a hydrogenase in a mediator free system under high levels of oxygen. Angew. Chem. Int. Ed. 52, 12313-12316 (2013).

13. Tschierlei, S. et al. Photochemical fate: the first step determines efficiency of $\mathrm{H}_{2}$ formation with a supramolecular photocatalyst. Angew. Chem. Int. Ed. 49, 3981-3984 (2010).

14. Fihri, A. et al. Cobaloxime-based photocatalytic devices for hydrogen production Angew. Chem. Int. Ed. 47, 564-567 (2008).

15. Khnayzer, R. S., McCusker, C. E., Olaiya, B. S. \& Castellano, F. N. Robust cuprous phenanthroline sensitizer for solar hydrogen photocatalysis. J. Am. Chem. Soc. 135, 14068-14070 (2013).

16. Han, Z. J., McNamara, W. R., Eum, M. S., Holland, P. L. \& Eisenberg, R. A nickel thiolate catalyst for the long-lived photocatalytic production of hydrogen in a noble-metal-free system. Angew. Chem. Int. Ed. 51, 1667-1670 (2012).

17. Du, P., Knowles, K. \& Eisenberg, R. A homogeneous system for the photogeneration of hydrogen from water based on a platinum(II) terpyridyl acetylide chromophore and a molecular cobalt catalyst. J. Am. Chem. Soc. 130, 12576-12577 (2008).

18. Goldsmith, J. I., Hudson, W. R., Lowry, M. S., Anderson, T. H. \& Bernhard, S. Discovery and high-throughput screening of heteroleptic iridium complexes for photoinduced hydrogen production. J. Am. Chem. Soc. 127, 7502-7510 (2005).

19. Hansen, S., Pohl, M. M., Klahn, M., Spannenberg, A. \& Beweries, T. Investigation and enhancement of the stability and performance of water reduction systems based on cyclometalated iridium(III) complexes. ChemSusChem. 6, 92-101 (2013).

20. Gärtner, F. et al. Synthesis, characterisation and application of iridium(III) photosensitisers for catalytic water reduction. Chem. Eur. J. 17, 6998-7006 (2011).

21. Zhang, P. et al. Homogeneous photocatalytic production of hydrogen from water by a bioinspired [Fe2S2] catalyst with high turnover numbers. Dalton Trans. 39, 1204-1206 (2010).

22. Wenger, O. S. Long-range electron transfer in artificial systems with $\mathrm{d}^{6}$ and $\mathrm{d}^{8}$ metal photosensitizers. Coord. Chem. Rev. 253, 1439-1457 (2009).

23. Tinker, L. L. et al. Visible light induced catalytic water reduction without an electron relay. Chem. Eur. J. 13, 8726-8732 (2007).

24. Metz, S. \& Bernhard, S. Robust photocatalytic water reduction with cyclometalated Ir(III) 4-vinyl-2,2' -bipyridine complexes. Chem. Commun. 46, 7551-7553 (2010).

25. Yu, Z. T., Yuan, Y. J., Cai, J. G. \& Zou, Z. G. Charge-neutral amidinate-containing iridium complexes capable of efficient photocatalytic water reduction. Chem. Eur. J. 19, 1303-1310 (2013) 
26. Yuan, Y. J. et al. Tricyclometalated iridium complexes as highly stable photosensitizers for light-induced hydrogen evolution. Chem. Eur. J. 19 , 6340-6349 (2013).

27. Yuan, Y. J. et al. Water reduction systems associated with homoleptic cyclometalated iridium complexes of various 2-phenylpyridines. ChemSusChem. 6, 1357-1365 (2013)

28. Zhang, W. et al. Nickel-thiolate complex catalyst assembled in one step in water for solar $\mathrm{H}_{2}$ production. J. Am. Chem. Soc. 133, 20680-20683 (2011).

29. Jaramillo, T. F. et al. Identification of active edge sites for electrochemical $\mathrm{H}_{2}$ evolution from $\mathrm{MoS}_{2}$ nanocatalysts. Science 317, 100-102 (2007).

30. Li, Y. G. et al. $\mathrm{MoS}_{2}$ nanoparticles grown on graphene: an advanced catalyst for the hydrogen evolution reaction. J. Am. Chem. Soc. 133, 7296-7299 (2011).

31. Kibsgaard, J., Chen, Z. B., Reinecke, B. N. \& Jaramillo, T. F. Engineering the surface structure of $\mathrm{MoS}_{2}$ to preferentially expose active edge sites for electrocatalysis. Nat. Mater. 11, 963-969 (2012).

32. Laursen, A. B., Kegnæs, S., Dahl, S. \& Chorkendorff, I. Molybdenum sulfidesefficient and viable materials for electro - and photoelectrocatalytic hydrogen evolution. Energy Environ. Sci. 5, 5577-5591 (2012).

33. Zong, X. et al. Enhancement of photocatalytic $\mathrm{H}_{2}$ evolution on CdS by loading $\mathrm{MoS}_{2}$ as cocatalyst under visible light irradiation. J. Am. Chem. Soc. 130, 7176-7177 (2008)

34. Xiang, Q. J., Yu, J. G. \& Jaroniec, M. Synergetic effect of $\mathrm{MoS}_{2}$ and graphene as cocatalysts for enhanced photocatalytic $\mathrm{H}_{2}$ production activity of $\mathrm{TiO}_{2}$ nanoparticles. J. Am. Chem. Soc. 134, 6575-6578 (2012).

35. Zong, X. et al. Visible light driven $\mathrm{H}_{2}$ production in molecular systems employing colloidal $\mathrm{MoS}_{2}$ nanoparticles as catalyst. Chem. Commun. 4536-4538 (2009).

36. Jiang, W. L. et al. Zwitterionic iridium complexes: synthesis, luminescent properties, and their application in cell imaging. Inorg. Chem. 49, 3252-3260 (2010).

37. Ye, J. X., Wang, Y., Xue, Q. J. \& Wu, X. D. Synthesis of highly stable dispersions of nanosized copper particles using L-ascorbic acid. Green Chem. 13, 900-904 (2011)

38. Sun, H. \& Hoffman, M. Z. Reductive quenching of the excited states of ruthenium(II) complexes containing 2,2' -bipyridine, 2,2' -bipyrazine, and 2,2' bipyrimidine ligands. J. Phys. Chem. 98, 11719-11726 (1994).

39. Cline, E. D., Adamson, S. E. \& Bernhard, S. Homogeneous catalytic system for photoinduced hydrogen production utilizing iridium and rhodium complexes. Inorg. Chem. 47, 10378-10388 (2008).

40. Merki, D. \& Hu, X. L. Recent developments of molybdenum and tungsten sulfides as hydrogen evolution catalysts. Energy Environ. Sci. 4, 3878-3888 (2011).

41. Mau, A. W. H., Johansen, O. \& Sasse, W. H. F. Xanthene dyes as sensitizers for the photoreduction of water. Photochem. Photobiol. 41, 503-506 (1985).
42. Thurston, T. R. \& Wilcoxon, J. P. Photooxidation of organic chemicals catalyzed by nanoscale $\mathrm{MoS}_{2}$. J. Phys. Chem. B 103, 11-17 (1999).

43. O'Regan, B. \& Grätzel, M. A low-cost, high-efficiency solar cell based on dyesensitized colloidal $\mathrm{TiO}_{2}$ films. Nature 353, 737-740 (1991).

44. Yum, G. H. et al. A cobalt complex redox shuttle for dye-sensitized solar cells with high open-circuit potentials. Nat. Commun. 3, 631 (2012).

45. Nazeeruddin, Md K. et al. Application of metalloporphyrins in nanocrystalline dye-sensitized solar cells for conversion of sunlight into electricity. Langmuir 20, 6514-6517 (2004).

46. Langdon, B. T., MacKenzie, V. J., Asunskis, D. J. \& Kelley, D. F. Electron injection dynamics of $\mathrm{Ru}^{\mathrm{II}}\left(4,4^{\prime} \text {-dicarboxy-2,2' -bipyridine }\right)_{2}$ cis(NCS $)_{2}$ adsorbed on $\mathrm{MoS}_{2}$ nanoclusters. J. Phys. Chem. B 103, 11176-11180 (1999).

\section{Acknowledgments}

This work was financially supported by the National Basic Research Program of China (Grant No. 2013CB632400), the National Science Foundation of China (Grant No. 20901038), and the Fundamental Research Funds for the Central Universities. We are also grateful to the Scientific Research Foundation for the Returned Overseas Chinese Scholars, State Education Ministry.

\section{Author contributions}

Y.J.Y. and Z.T.Y. contributed the conception, designed the experiments, analyzed the data and participated in writing the paper; Y.J.Y. and J.G.C. carried out the experiments; X.J.L. and J.Z.G. provided the electron microscopy characterization; Z.T.Y. and Z.G.Z. supervised the project. All authors discussed the results.

\section{Additional information}

Supplementary information accompanies this paper at http://www.nature.com/ scientificreports

Competing financial interests: The authors declare no competing financial interests.

How to cite this article: Yuan, Y.-J. et al. Hydrogen Photogeneration Promoted by Efficient Electron Transfer from Iridium Sensitizers to Colloidal $\mathrm{MoS}_{2}$ Catalysts. Sci. Rep. 4, 4045; DOI:10.1038/srep04045 (2014).

(c) (i) (2) This work is licensed under a Creative Commons Attribution-

BY NC SA NonCommercial-ShareAlike 3.0 Unported license. To view a copy of this license, visit http://creativecommons.org/licenses/by-nc-sa/3.0 